\title{
Antimicrobial-resistant bacteria in the community setting
}

\section{E. Yoko Furuya* and Franklin D. Lowy ${ }^{* \neq}$}

Abstract | Over the past decade, antimicrobial resistance has emerged as a major publichealth crisis. Common bacterial pathogens in the community such as Streptococcus pneumoniae have become progressively more resistant to traditional antibiotics. Salmonella strains are beginning to show resistance to crucial fluoroquinolone drugs. Community outbreaks caused by a resistant form of Staphylococcus aureus, known as communityassociated meticillin (formerly methicillin)-resistant Staphylococcus aureus, have caused serious morbidity and even deaths in previously healthy children and adults. To decrease the spread of such antimicrobial-resistant pathogens in the community, a greater understanding of their means of emergence and survival is needed.

The introduction of antimicrobial drugs, most notably penicillin, was thought to herald the beginning of the end of bacterial infections. Unfortunately, the rapid recognition of penicillin resistance within a year of its introduction disabused physicians of this notion ${ }^{1}$. Initially, infections caused by antimicrobial-resistant bacteria occurred mainly in hospital settings, where antimicrobial use was most extensive. Bacteria carrying antimicrobial-resistance genes had a survival advantage that facilitated dissemination in this setting. Factors such as the close proximity of sick patients, receiving antimicrobial agents and often cared for by the same healthcare personnel, contributed to the increased risk of developing infections caused by antimicrobial-resistant pathogens. Efforts to reduce healthcare-associated infections, especially those due to antimicrobial-resistant bacteria, are now a major focus of healthcare facilities.

More recently, there has been an equally disturbing trend that has received less attention: the spread of antimicrobial-resistant bacteria within the community. Despite the increasing prevalence of organisms such as penicillin-resistant pneumococci, quinolone-resistant enterobacteriaceae and community-associated meticillin (formerly methicillin)-resistant Staphylococcus aureus (CA-MRSA), there has been limited public attention focused on the community as an important reservoir for antimicrobial resistance.

The foremost reason for this trend is the increasing volume of antimicrobial usage around the world, particularly in the community setting. Studies indicate a direct correlation between antimicrobial use and the extent of antimicrobial resistance ${ }^{2}$. Figures vary widely, but it has been determined that approximately 3 million pounds in weight of antimicrobial drugs are used by humans annually ${ }^{3}$. Most of these drugs are used in the outpatient setting, and studies estimate that half of outpatient antimicrobials are prescribed for inappropriate indications, such as viral illnesses ${ }^{4,5}$ (FIG. 1).

These studies do not take into account antimicrobials that are acquired without doctors' prescriptions; in fact, the sharing of antimicrobial drugs among friends and family members occurs not infrequently. Furthermore, antimicrobials are often obtained over the counter, legally in many countries and illicitly in the United States. Moreover, even more antimicrobial drugs are used in food animals compared with humans, approximated at 30 million pounds a year ${ }^{3}$. These factors create an environment that provides antibiotic-resistant bacteria with a potential survival advantage.

\section{Mechanisms of antimicrobial resistance}

Bacteria acquire antimicrobial resistance as a result of chromosomal mutations or the horizontal exchange of genetic material among related or unrelated bacterial species $^{6-12}$. Genetic exchange occurs in various ways, including transformation, transduction and conjugation (FIG. 2). These genetic events occur in the presence or absence of antibiotics. There are, however, several ways in which antimicrobial usage contributes to antimicrobial resistance: a concurrent selective effect, a subsequent competitive effect and bacterial genetic transfer. In the concurrent selective effect, during antimicrobial administration, susceptible organisms are killed, whereas organisms 


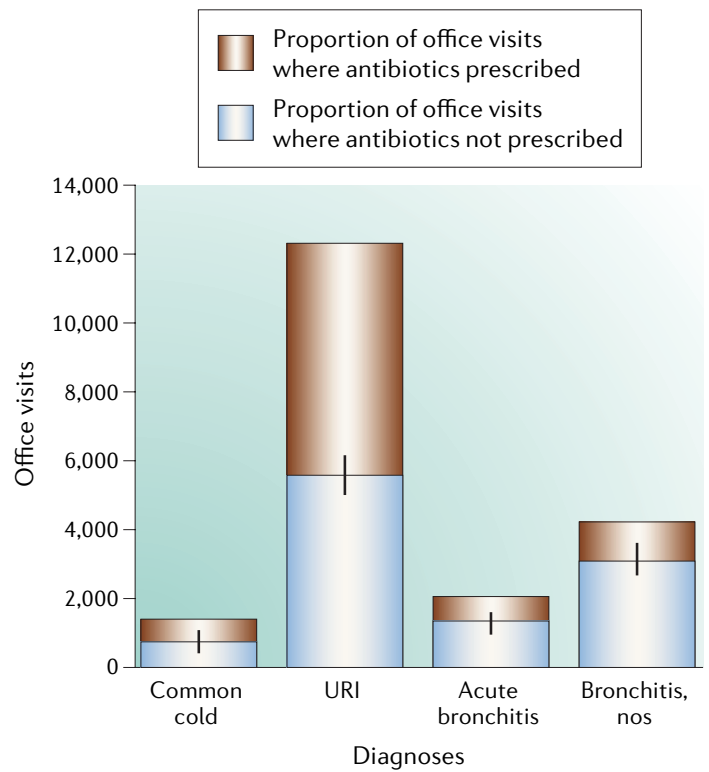

Figure 1 Rates of prescriptions for the 'common cold', upper-respiratory-tract infections (URIs) and bronchitis in children and adolescents. Antibiotics are prescribed during a significant proportion of outpatient office visits for non-bacterial illnesses. Data are from the National Ambulatory Medical Care Survey 1992. Error bars represent $95 \%$ confidence intervals. nos, not otherwise specified. Reproduced with permission from REF. 5 ๑ (1998) American Medical Association.

that are resistant to the drug persist and therefore gain a survival advantage. In the subsequent competitive effect, the antimicrobial agent eradicates non-pathogenic commensal organisms as well as pathogens, which creates a void in the normal microbiotic environment that can predispose an individual to colonization with less innocuous (and drug-resistant) organisms ${ }^{13}$. Last, bacterial genetic transfer allows for the survival of antimicrobial-resistance traits, not only in the genetic progeny of resistant strains but in unrelated strains of bacteria.

For a resistant pathogen to be 'successful', its resistance mechanism must be sustainable even in the absence of antibiotic selective pressure. The additional genetic machinery must not place a significant survival constraint on the pathogen when compared with the antibioticsusceptible strains. For instance, the prediction that recently described isolates of vancomycin-resistant S. aureus (VRSA) are far more likely to disseminate than isolates of intermediate susceptibility to vancomycin (VISA) is based in part on the glycopeptide-dependent expression of the resistance genes in the former, in contrast to the constitutive expression of the resistance genes in the latter. VISA isolates require additional peptidoglycan synthesis, which imposes an increased burden on the cell's synthetic machinery ${ }^{14-17}$. By contrast, VRSA strains express resistance genes only on exposure to glycopeptides by synthesizing a unique depsipeptide ${ }^{18}$.

In addition to the selective effects of antibiotics, there are other factors that contribute to the spread of antibiotic-resistant pathogens in the community. For example, there are bacterial determinants that facilitate colonization and survival in diverse environmental settings ${ }^{19}$. Some bacteria such as Clostridium difficile can exist in the form of spores; these spores can survive on environmental surfaces and are resistant to the bactericidal action of many biocides ${ }^{20}$. This hardiness is one factor that contributes to hospital outbreaks of C. difficile. Biofilms are structural matrices that allow organisms to adhere to surfaces; they form on various indwelling clinical devices and limit the access of antimicrobial agents to the bacteria within them, making eradication difficult ${ }^{21,22}$. Biofilms have been described for Staphylococcus epidermidis, Pseudomonas aeruginosa and Legionella species, among others ${ }^{22}$. S. aureus uses several mechanisms to adhere to nasal epithelial cells, whereby it colonizes the nasopharynx; these include clumping factor $\mathrm{B}^{23}$ and wall teichoic $\mathrm{acid}^{24}$. Such bacterial determinants, when associated with antimicrobial-resistant bacteria, can assist in their persistence and their spread.

Furthermore, social networks of individuals (for example, households, schools and childcare facilities) that serve either as a reservoir for these bacteria or as a means for their transmission are crucial to the success of antimicrobial-resistant bacteria ${ }^{25-28}$ (TABLE 1).

We discuss below several examples of antibioticresistant bacteria, illustrating different elements that contribute to their success in the community setting.

\section{Penicillin-resistant Streptococcus pneumoniae}

Streptococcus pneumoniae is a Gram-positive coccus that is a common cause of lobar pneumonia, bacterial meningitis and otitis media. It grows in pairs and chains in liquid media, and most pathogenic strains are encapsulated, a feature that allows S. pneumoniae to avoid phagocytosis by the host immune system. It adheres to, and replicates in, the nasopharynx, which is a site for colonization. 5 to $10 \%$ of adults are colonized, whereas the colonization rate for children is higher. Invasive infection is most common in children under 2 years of age and in adults older than 65 years $^{29}$.

The first clinically recognized isolates of penicillinresistant $S$. pneumoniae (PRSP) were not reported until 1967 , more than twenty years after the introduction of penicillin ${ }^{30}$. This resistance is conferred by alterations in one or more penicillin-binding proteins (PBPs) that result in a decreased affinity for the drug. Typically, the more PBP mutations, the higher the level of penicillin resistance, and the minimum inhibitory concentration (MIC) increases in a stepwise manner through these sequential genetic events ${ }^{31}$. These altered PBPs seem to result from the incorporation of foreign DNA sequences by recombination, which results in 'mosaic' genes; the donor of the foreign DNA is probably a viridans streptococcal species, which are commensal organisms that reside in the oropharyn ${ }^{32}$.

Once the PRSP was established, it proved to be triply successful in that it was sustainable, transmissible and sufficiently virulent. The resistance persists even in the absence of antimicrobials, as resistance genes are constitutively expressed ${ }^{33}$. Until the last decade, the level of penicillin resistance in S. pneumoniae in the United States was not significant, but the 1990s have seen a 
a Bacterial transformation

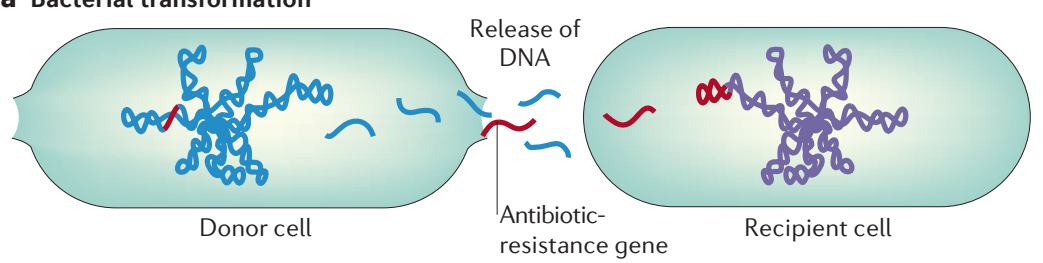

b Bacterial transduction

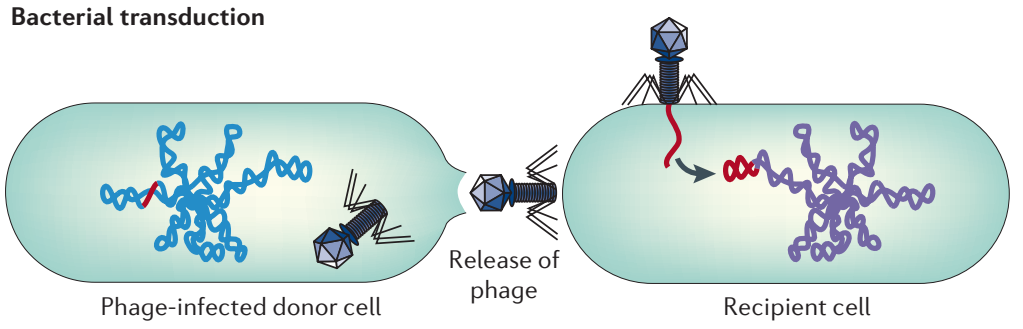

C Bacterial conjugation

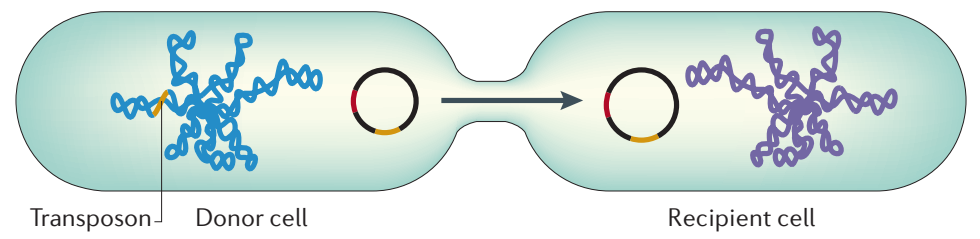

Figure 2 | Horizontal gene transfer between bacteria. a|Transformation occurs when naked DNA is released on lysis of an organism and is taken up by another organism. The antibiotic-resistance gene can be integrated into the chromosome or plasmid of the recipient cell. $\mathbf{b}$ | In transduction, antibioticresistance genes are transferred from one bacterium to another by means of bacteriophages and can be integrated into the chromosome of the recipient cell (lysogeny). c | Conjugation occurs by direct contact between two bacteria: plasmids form a mating bridge across the bacteria and DNA is exchanged, which can result in acquisition of antibiotic-resistance genes by the recipient cell. Transposons are sequences of DNA that carry their own recombination enzymes that allow for transposition from one location to another; transposons can also carry antibiotic-resistance genes.

Clonal dissemination The spread of one or several clones of an organism throughout a region or population. considerable increase in this level. Surveillance studies indicate that in the United States in 2001 the frequency of reduced susceptibility of $S$. pneumoniae to penicillin was $38.8 \%$, with high-level penicillin resistance (MIC $\geq 2$ ) being $26.3 \%$ (REF. 34).

On an individual level, the most common risk factor for having a PRSP infection is the previous use of antimicrobials ${ }^{35,36}$. Furthermore, there have been many ecological studies showing a population-level association between antibiotic use and resistance ${ }^{37,38}$. Goossens et al. ${ }^{2}$ showed this correlation on the basis of data from the European Surveillance of Antimicrobial Consumption (ESAC) project, a network that has linked surveillance systems across Europe, allowing for a comparison of antibiotic-use data across 32 countries. These authors found significant variation between countries in their volume of antibiotic use and in their resistance rates for a wide range of bacteria, with the highest rates of antibiotic use and resistance in southern Europe. This correlation was highly significant for penicillin or cephalosporin use and PRSP (FIG. 3).

A surprisingly limited number of clones are responsible for most PRSP, illustrating the role of clonal dissemination (BOX 1) in its spread. In 1998, Corso et al. ${ }^{39}$ used pulsed-field gel electrophoresis to show that, of 328 PRSP strains in the United States, only 10 clones were responsible for $85 \%$ of invasive PRSP disease. An example of clonal transcontinental PRSP transmission is the report by Soares et al..$^{40}$ that documents the spread of the Spanish clone serotype 6B to Iceland, possibly as a result of travel by Icelanders to Spain.

Other studies have shown that childcare centres are important settings for the clonal spread of PRSP, as the paediatric population is a large reservoir of nasopharyngeal S. pneumoniae colonization and is also the frequent recipient of antibiotics for upper-respiratory-tract infections ${ }^{41,42}$. It is noteworthy that 40 to $60 \%$ of toddlers and children in childcare facilities are nasopharyngeally colonized with pneumococci ${ }^{43}$.

In weighing the relative importance of clonal dissemination and antimicrobial use in the increase in PRSP, McCormick et al. ${ }^{44}$ used mathematical modelling to determine which factor contributed more significantly to the large geographic variation in PRSP in the United States. Their mathematical transmission model indicated that antimicrobial selective pressure was the key determinant.

Therefore, penicillin resistance in S. pneumoniae originated through the acquisition of foreign DNA leading to altered PBPs; it then spread as a result of antibiotic selective pressure, along with clonal dissemination, in facilities such as childcare centres where a reservoir of PRSP was established.

\section{Antimicrobial resistance and the food industry}

Food animals are a rich environment for the bacterial transfer of genetic material between pathogens and commensal non-pathogens. When this factor is coupled with the enormous selective pressure of large-scale antimicrobial use for growth, resistance becomes almost inevitable.

There are many problems with antimicrobial-use practices in the food-animal industry, including largescale use of low-dose, long-duration antimicrobials for non-therapeutic purposes; mass antimicrobial administration, known as metaphylaxis, to treat a small number of sick animals; use of antimicrobials in the same class as those used in humans; and a lack of adequate regulation of antimicrobial use $\mathrm{e}^{45}$. Most antimicrobial administration in food animals is not for treatment, or even prophylaxis, of infection; on the contrary, it is for growth-promotion purposes. Therefore, antimicrobials are administered to herds of animals at subtherapeutic doses, often for weeks to months, providing the perfect setting for selection of drug-resistant bacteria.

The selective pressure of antibiotics in animals can lead to antibiotic resistance both in animals and in humans who come into contact with these animals. Levy et al. ${ }^{46}$ conducted a landmark study in 1976 in which chickens were given tetracycline in their feed. Subsequent analysis of their intestinal bacteria revealed tetracycline-resistant organisms. Moreover, the humans who lived on the farm also developed tetracycline-resistant intestinal flora. 
Table 1 | Community reservoirs of antimicrobial-resistant bacteria

\begin{tabular}{|c|c|c|c|}
\hline Bacterial species & $\begin{array}{l}\text { Common types of antimicrobial } \\
\text { resistance }\end{array}$ & Types of infection & Community reservoirs \\
\hline Streptococcus pneumoniae & $\begin{array}{l}\text { Penicillin, macrolides, cephalosporins, } \\
\text { tetracyclines }\end{array}$ & $\begin{array}{l}\text { Otitis media, pneumonia, } \\
\text { sinusitis, meningitis }\end{array}$ & $\begin{array}{l}\text { Childcare facilities }{ }^{41,42} \text {, paediatric } \\
\text { populations }^{121}\end{array}$ \\
\hline Streptococcus pyogenes & Macrolides, tetracyclines & $\begin{array}{l}\text { Pharyngitis, impetigo, } \\
\text { cellulitis }\end{array}$ & $\begin{array}{l}\text { Childcare facilities }{ }^{122,123}, \text { paediatric } \\
\text { populations }{ }^{124,125}, \text { schools }^{126}\end{array}$ \\
\hline \multicolumn{4}{|l|}{ Staphylococcus aureus } \\
\hline Community-associated & Meticillin, cephalosporins, macrolides & $\begin{array}{l}\text { Skin, soft tissue, pneumonia, } \\
\text { sepsis }\end{array}$ & $\begin{array}{l}\text { Native Americans } s^{127} \text {, homeless people }{ }^{128} \text {, } \\
\text { soldiers }^{109} \text {, prisoners }{ }^{105} \text {, childcare } \\
\text { facilities }^{129} \text {, injection-drug users }\end{array}$ \\
\hline Healthcare-associated & $\begin{array}{l}\text { Meticillin, cephalosporins, quinolones, } \\
\text { aminoglycosides, macrolides }\end{array}$ & $\begin{array}{l}\text { Endocarditis, pneumonia, } \\
\text { sepsis }\end{array}$ & $\begin{array}{l}\text { People exposed to healthcare facilities } \\
\text { such as nursing homes }{ }^{131} \text {, dialysis }{ }^{83} \text {, recent } \\
\text { surgery or hospitalization }\end{array}$ \\
\hline Enterococcus spp. & Ampicillin, vancomycin, aminoglycosides & Sepsis, urinary tract & $\begin{array}{l}\text { People exposed to hospital care (in the } \\
\text { United States) })^{132} \text {, food animals (exposure } \\
\text { to avoparcin in Europe) })^{133}\end{array}$ \\
\hline Neisseria gonorrhoeae & Penicillin, cephalosporins, quinolones & $\begin{array}{l}\text { Urethritis, pelvic } \\
\text { inflammatory disease }\end{array}$ & Commercial sex workers ${ }^{134}$ \\
\hline $\begin{array}{l}\text { Salmonella spp. } \\
\text { (non typhoidal) }\end{array}$ & Cephalosporins, quinolones, tetracyclines & Diarrhoea & Food animals (poultry, cows) ${ }^{66,67}$ \\
\hline Escherichia coli & Trimethoprim, sulphonamides, quinolones & Urinary tract, diarrhoea & Childcare facilities $^{135}$ \\
\hline Campylobacter jejuni & Erythromycin, quinolones & Gastroenteritis & Food animals (poultry) ${ }^{136}$ \\
\hline
\end{tabular}

Vancomycin-resistant enterococcus. Many antimicrobials used in food animals belong to the same classes as those used in humans, leading to concerns about crossresistance. Avoparcin, a drug similar to vancomycin, has been used in Europe for growth promotion of food animals since the 1970s, and vancomycin-resistant enterococcus (VRE) was subsequently first described in 1988 (REF. 47). VRE has since been isolated from food animals in Denmark and Germany, among other countries, and epidemiological studies have established a link with avoparcin use ${ }^{48,49}$. Also, the same strains of VRE have been found in animals and humans, further validating the association with avoparcin ${ }^{50,51}$. So, whereas nosocomial spread is the main means of VRE transmission in the United States, this animal-tohuman spread in Europe occurred outside the hospital setting and seems to explain why VRE carriage is more commonly found in the European environment and community ${ }^{50,52-54}$. For unclear reasons, however, human infections caused by VRE still occur less frequently in Europe than in the United States, where avoparcin has never been used.

Non-typhoidal fluoroquinolone-resistant Salmonella. Non-typhoidal Salmonella is another organism that has developed resistance linked to antimicrobial use in animals. Salmonellae are Gram-negative bacilli of the family Enterobacteriaceae. Whereas Salmonella enterica serovar Typhi colonizes humans only, non-typhoidal salmonellae colonize and infect a wide range of animals in addition to humans, including poultry, cows and other farm animals. These animals serve as a reservoir for Salmonella and can lead to foodborne infections in humans; animals can also become ill from the organism, the most common manifestation being diarrhoea.
Human infections due to non-typhoidal Salmonella are almost always a result of contaminated-food ingestion, with an estimated 1.4 million such infections occurring in the United States each year ${ }^{55}$. Contamination of food products with Salmonella is common; for example, a recent study that tested 200 meat samples from supermarkets in the Washington DC area found that $20 \%$ contained Salmonella species ${ }^{56}$. Furthermore, a relatively low inoculum - less than $10^{3}$ organisms - can cause disease in humans ${ }^{57}$. A far less common mode of transmission is by exposure to exotic pets such as reptiles and even rodents ${ }^{58,59}$.

The usual clinical syndrome is an acute gastroenteritis with nausea, vomiting, diarrhoea and often fever. This syndrome is typically self-limited, but more serious infections can result, such as bacteraemia, endovascular infections and bone and joint infections, particularly at extremes of age or in immunocompromised individuals.

Antimicrobial resistance has been on the rise in nontyphoidal salmonellae around the world. The Enter-net surveillance system in Europe found that, of 27,000 cases of human salmonellosis in 2000, nearly $40 \%$ were resistant to at least one antimicrobial agent, with $18 \%$ being resistant to 4 or more unrelated antimicrobials ${ }^{60}$. Resistance is thought to be acquired both by chromosomal gene mutation and by horizontal transfer of plasmids ${ }^{61-63}$. In developing countries, resistance might be due to unregulated antimicrobial dispensing for human use $^{64,65}$. By contrast, in developed countries, resistance seems to be largely a consequence of the extensive use of antimicrobials in food animals to improve growth rate. For instance, Denmark and Taiwan have seen significant increases in quinolone-resistant Salmonella enterica species in humans in the setting of growing fluoroquinolone use in food animals ${ }^{66,67}$. 


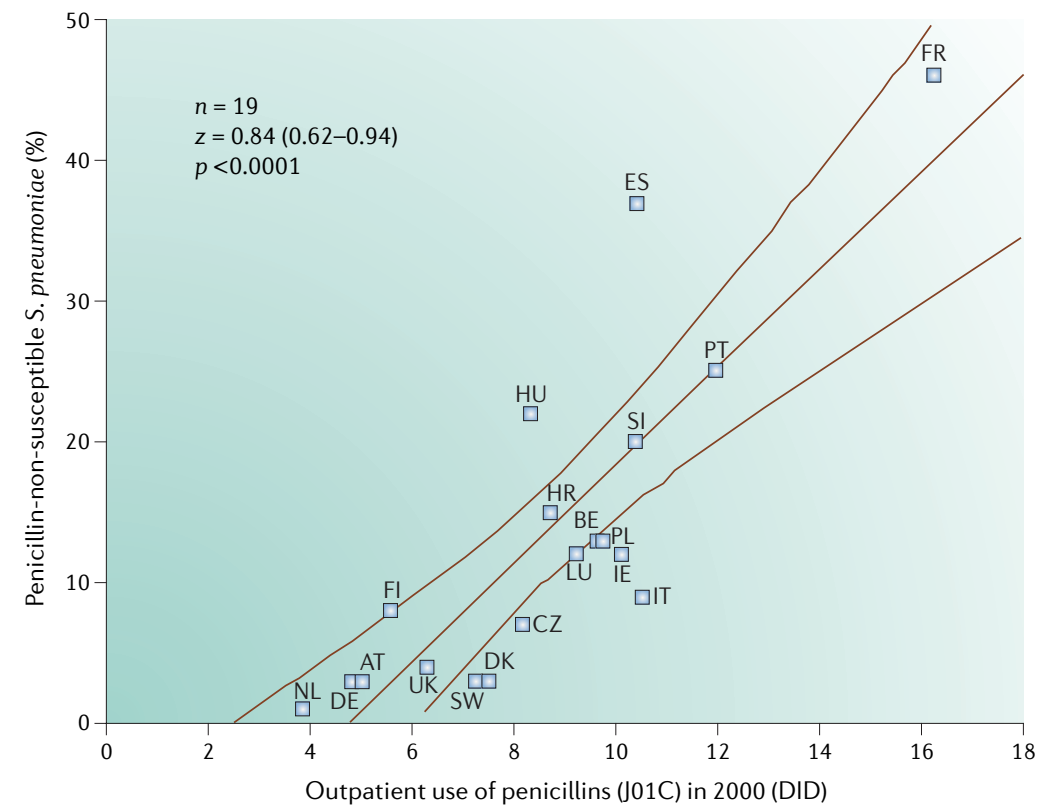

Figure 3 | Correlation between penicillin use and prevalence of penicillin-nonsusceptible Streptococcus pneumoniae. European countries with greater outpatient use of penicillin have higher rates of penicillin-non-susceptible S. pneumoniae. AT, Austria; BE, Belgium; CZ, Czech Republic; DE, Germany; DK, Denmark; FI, Finland; FR, France; HR, Croatia; HU, Hungary; IE, Ireland; IT, Italy; LU, Luxembourg; NL, The Netherlands; PL, Poland; PT, Portugal; SI, Slovenia; ES, Spain; UK, England only. DID, the number of defined daily doses per 1000 inhabitants daily. Reproduced with permission from REF. 2 ๑ (2005) Elsevier.
2001, 1\% of all Salmonella isolates in the United States had decreased susceptibility to quinolones (defined as $\mathrm{MIC} \geq 0.25 \mu \mathrm{g} / \mathrm{ml})^{68}$. Although this is a small number, only fifteen years ago the number was virtually zero. In the United Kingdom, low-level resistance to the fluoroquinolone ciprofloxacin (MIC $0.125-1 \mathrm{mg} / \mathrm{l}$ ) in non-typhoidal Salmonella was reported as 4\% in 1996 (REF. 69).

The main drug-resistant strain of concern at present is Salmonella Typhimurium DT104. This is a multidrug-resistant strain with a chromosome- and integronencoded $\beta$-lactamase ${ }^{61}$ that was first described in the United Kingdom in the 1980s but became increasingly widespread throughout the world during the 1990s, causing infections in both animals and humans ${ }^{70-72}$. During this time, some strains of $S$. Typhimurium DT104 acquired decreased susceptibility to quinolones as a result of a chromosomal mutation in the $g y r A$ gene that encodes topoisomerase II and IV, the bacterial targets of the quinolones ${ }^{73}$.

In the United Kingdom, S. Typhimurium DT104 with reduced susceptibility to quinolones was reported several years after the fluoroquinolone enrofloxacin was licensed for animal use in 1993 (REF. 74). In the United States, quinolone use in food animals is restricted to therapeutic use only; however, this might be sufficient to lead to quinolone-resistant Salmonella infections in humans.

Although the total number of resistant Salmonella infections in humans that are directly traceable to antibiotic use in food animals is small, the potential for a rapid increase of this problem is substantial. Also, although human antimicrobial use is not the main cause of resistant Salmonella, it can increase the risk of acquisition in some cases. In a healthcare-associated outbreak of fluoroquinolone-resistant Salmonella in Oregon, USA, it was found that treatment with a fluoroquinolone within the past six months prior to infection was associated with an increased risk of infection $^{75}$. This indicates that the competitive effect, in which eradication of benign commensals by an antimicrobial agent increases the risk of subsequent infection, can be involved in Salmonella infections.

\section{Box 1 | Antibiotic selective pressure versus clonal dissemination}

Many drug-resistant microorganisms spread by a combination of antibiotic selective pressure and clonal dissemination. There is limited understanding of the interaction between these two factors.

\section{Antibiotic selective pressure}

Antibiotic selective pressure refers to the impact of antimicrobial use on a population of organisms, in which organisms that are resistant to the antibiotic gain a survival advantage over those susceptible to the antibiotic. This bacterial population includes both potential pathogens and the less virulent commensal flora. Antibiotic-resistant pathogens gain an advantage, not only because they are selected by the antibiotic, but because elimination of the antibiotic-susceptible commensal flora creates a niche into which resistant pathogens can spread and establish a reservoir for subsequent infections. Prevention of antibiotic selective pressure would focus on limiting antimicrobial use.

\section{Clonal dissemination}

Clonal dissemination refers to the spread of specific clones of an organism throughout a community. These clones are thought to be more transmissible than other clones, for unknown reasons. Strains that carry antibiotic-resistance genes might be more likely to clonally disseminate under conditions of antibiotic selective pressure (for example, farms that use extensive amounts of antibiotics in their feed). Prevention of clonal dissemination would focus on issues such as infection control and hand hygiene. 
Restriction of all antimicrobial use in food animals is indicated, as has been successfully accomplished in countries such as Denmark and Sweden ${ }^{76,77}$, but quinolone restriction in particular is crucial, as this class of drugs is a key component of antimicrobial management in humans.

\section{Community-associated MRSA}

Staphylococcus aureus is a Gram-positive coccus that is commonly found on the skin and in the nasopharynx of humans. Approximately 30 to $50 \%$ of the population is colonized with this organism ${ }^{78,79}$, and colonization is a risk factor for subsequent infection ${ }^{80}$. S. aureus can cause a wide range of clinical disease, including skin and soft tissue infections (cellulitis, folliculitis and abscesses), pneumonia, bloodstream infections, infective endocarditis and osteomyelitis. Certain populations are at higher risk of colonization, including type I diabetics ${ }^{81}$, intravenousdrug users ${ }^{82}$, haemodialysis patients ${ }^{83}$, surgical patients ${ }^{84}$ and those with $\mathrm{AIDS}^{85}$. One characteristic of $S$. aureus is its ongoing ability over the years to acquire resistance mechanisms as new antimicrobials are targeted against it. For example, meticillin was introduced in 1960, and the first report of MRSA appeared shortly thereafter ${ }^{86}$.

MRSA has been a steadily growing problem in healthcare facilities over the past few decades $-50 \%$ of $S$. aureus isolated from intensive-care units in the United States is resistant to meticillin ${ }^{87}$. European data show a wide range of MRSA prevalence: from $<1 \%$ in northern Europe to $>40 \%$ in southern and western Europe, including the United Kingdom, Ireland, Italy and Greece; these data represent the 1999-2002 time period and include both inpatient and outpatient isolates ${ }^{88}$. This healthcareassociated spread was due to a combination of concentrated antimicrobial use in a closely cohorted population of sick patients, resulting in extensive dissemination of a limited number of clones. In fact, molecular epidemiological studies confirm that, until recently, only five major 'pandemic clones' of MRSA have been responsible for most worldwide MRSA ${ }^{89,90}$. Despite this growing healthcare-associated reservoir of MRSA, the organism was uncommon in the community, apart from certain small, closed societies (such as Western Australian aboriginal communities $)^{91}$. The MRSA that did appear in the community could usually be traced back to direct or indirect healthcare-associated exposure.

In the past decade, we have begun to see individuals without the usual risk factors (hospitalization or other institutionalization, antibiotic use, dialysis or chronic wounds) with MRSA infections; this phenomenon has been called 'community-associated MRSA' (CA-MRSA). There are little published data on the true community incidence of CA-MRSA, but a recent population-based surveillance study in the United States found incidences of 18.0 and 25.7 cases per 100,000 people in Baltimore and Atlanta, respectively ${ }^{92}$. As opposed to healthcareassociated strains, which tend to cause a wide variety of infections (for example, wound infections, catheterassociated bacteraemias or prosthesis infections), CA-MRSA most commonly causes a specific syndrome of skin manifestations, particularly folliculitis and abscesses.
More severe infections such as necrotizing pneumonia, necrotizing fasciitis and sepsis have also been reported ${ }^{93-95}$.

CA-MRSA is distinguished from healthcare-associated MRSA (HA-MRSA) in part by the mobile chromosomal element known as the staphylococcal chromosomal cassette (SCC), which carries the meticillin-resistance gene mec. HA-MRSA more frequently carries an SCCmec element from groups I-III; CA-MRSA contains a novel SCCmec type known as SCCmec type IV (and more recently SCCmec type V). Because of its relatively small size $(21 \mathrm{~kb})$ and its intact recombinase genes, SCCmec type IV is more mobile and can insert into a wider array of staphylococcal genetic backgrounds ${ }^{96-99}$. As a result, CA-MRSA comprises a more genetically diverse group of strains than HA-MRSA. Also, owing to the absence of other antimicrobial-resistance genes on SCCmec type IV, CA-MRSA tends to be more susceptible to non- $\beta$-lactam antibiotics than HA-MRSA.

Having described the characteristics that distinguish CA-MRSA from HA-MRSA, it is also important to acknowledge the progressive blurring of the two categories. HA-MRSA has also disseminated in the community; for example, there are studies that describe the transmission of MRSA from patients to their household contacts in the community ${ }^{100}$. Conversely, CA-MRSA has now been around long enough to enter healthcare settings and cause outbreaks in hospitals: recently, a CA-MRSA strain caused an outbreak of mastitis in postpartum patients on a maternity ward ${ }^{101}$.

Therefore, like the PRSP and the quinolone-resistant Salmonella, CA-MRSA seems to have arisen through the acquisition of a foreign genetic element, SCCmec type IV (most likely from a coagulase-negative staphylococcal species $)^{102}$. In contrast to the first two examples, however, its origin is less clearly associated with antimicrobial selective pressure, at least on the individual level - many patients with CA-MRSA have not received such drugs. This raises the question of whether the CA-MRSA strains possess other survival advantages, such as colonization factors or a more rapid growth rate that would facilitate survival ${ }^{103,104}$.

Clonal dissemination does seem to have an important role in the spread of CA-MRSA, as outbreaks have been reported in some well-defined epidemiological groups, including children in childcare facilities, prison inmates, athletes, intravenous-drug users and military recruits ${ }^{105-108}$. During the investigation of a CA-MRSA outbreak among military recruits, $2.7 \%$ (24 out of 874 ) of the workers at the military facility were found to be nasally colonized with CA-MRSA, a much higher prevalence than in the general population ${ }^{109}$. Features that were common to these outbreaks included close contact, crowding, contaminated items, poor hygiene and compromised skin integrity. At present, there are limited data on what determines the efficiency of CA-MRSA clonal dissemination.

It is of interest that this emerging resistant community pathogen might not have arisen as a direct effect of antimicrobial use. Instead, its rapid spread is associated with a confluence of elements that combine bacterial virulence factors (such as the Panton-Valentine leukocidin) with unique social and environmental settings. 


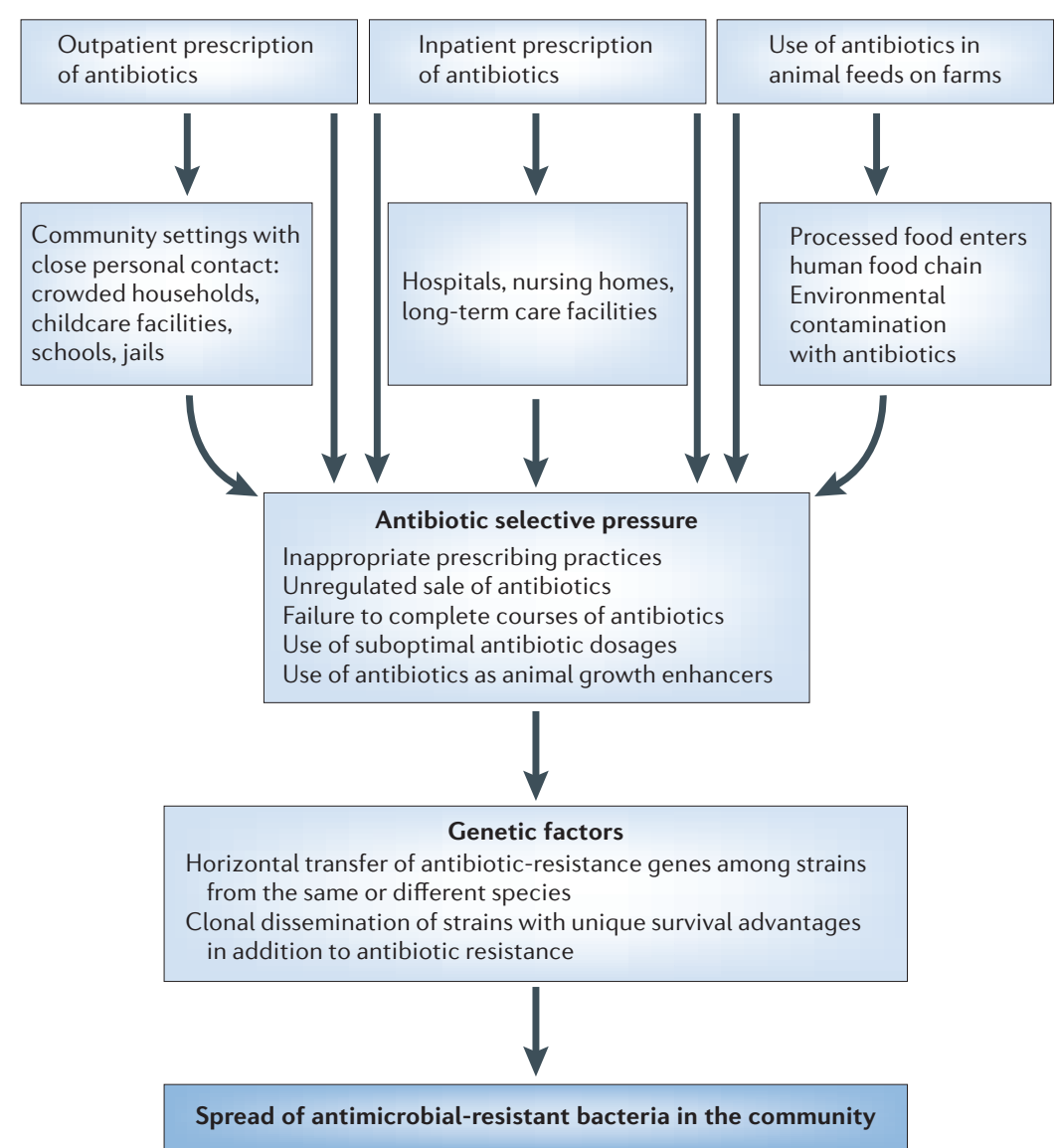

Figure 4 | Factors that contribute to the spread of antimicrobial resistance in the community. Antimicrobial resistance in the community setting is a multifactorial problem. Increased antimicrobial usage around the world is the foremost reason for this spread. Social networks of individuals (households, schools and childcare facilities) serve either as a reservoir for these bacteria or as a means for their transmission. Hospitals, nursing homes and long-term care facilities also serve as reservoirs of antibiotic-resistant organisms. The discharge into the community of patients exposed to antibiotics in healthcare facilities also contributes to the spread of resistant organisms. The use of antimicrobials in food animals is an important contributing cause. The acquisition of a foreign genetic resistance element, antimicrobial selective pressure and clonal dissemination are key factors, which carry different weight for different organisms and geographic locations. setting can trace their resistance back to a unique mix of factors, with antibiotic selective pressure having a different magnitude of importance for each. The complicated nature of antimicrobial resistance requires a multipronged approach to combat it.

Curbing the volume of antimicrobial use in both humans and animals should of course be a priority. Although some studies indicate that reducing antimicrobial use might not lead to a rapid, or even any, reduction in resistance ${ }^{110}$, other studies have shown more hope. Finland instituted national guidelines in 1991 to decrease macrolide use, and a subsequent $42 \%$ reduction in macrolide use was followed by a $48 \%$ reduction in the prevalence of group A streptococci that were resistant to macrolides ${ }^{111}$. Denmark has seen success in decreasing levels of VRE in broilers (from $72.7 \%$ in 1995 to $5.8 \%$ in 2000) after the government banned avoparcin use in 1995 (REF. 76), although it is unclear what effect this has had on human VRE infections. The United States has historically lagged behind Europe in banning or restricting the use of antibiotic growth promoters, but in July 2005 a decision was made by the Food and Drug Administration to ban the use of enrofloxacin for poultry (see Online links box).

In addition to reducing the total volume of antibiotic use in animals and humans, attention should be focused more specifically on reducing the use of low-potency, long-duration antibiotics. There has been evidence to suggest that using antibiotics in such a manner increases the risk of PRSP carriage ${ }^{112}$. A randomized controlled trial in children showed that short-course (5-day), highdose amoxicillin for upper-respiratory-tract infections led to the isolation of significantly lower levels of PRSP after therapy than conventional (10-day) courses $(24 \%$ versus $32 \%)^{113}$.

As clonal dissemination has a role in the spread of many antimicrobial-resistant pathogens, decreasing antibiotic usage alone would be insufficient in halting their proliferation. Investigation of the modes of transmission of resistant pathogens will result in a better understanding of their spread and in more effective intervention strategies. Social-network theory has been increasingly used to understand the transmission of certain infectious diseases, such as HIV, tuberculosis and sexually transmitted diseases ${ }^{25-28}$. This theory views the world as a series of networks linked by social settings and behaviours. By constructing such networks, the transmission of pathogens can be traced back to common sources. More recently, social networking has been combined with molecular epidemiology to strengthen it as an investigational tool ${ }^{26,114}$. By using these methodologies, perhaps we can create interventions to break the networks by which antimicrobial-resistant bacteria are spread.

Last, vaccine development and use provide some hope in the battle against antimicrobial resistance. A 7-valent pneumococcal conjugate vaccine (Prevnar) was licensed for use in young children in 2000-2001, and subsequent data on PRSP prevalence have been mixed. Some studies have shown an increase in S. pneumoniae resistance in the past few years ${ }^{115-117}$, raising concerns that vaccine serotypes might simply be replaced with 
non-vaccine serotypes, and that penicillin resistance might rise in the latter. In fact, a mathematical-modelling study has predicted that, after 20 years, any decrease in penicillin-resistant strains due to the vaccine would not be sustained, as antibiotic selective pressure seemed to be a more important determinant of the persistence of resistance ${ }^{118}$. However, other studies report a decrease in childhood rates of overall invasive pneumococcal disease and of disease caused by pneumococci not susceptible to penicillin ${ }^{119,120}$. In one population-based study, a decrease in invasive pneumococcal disease was also seen in adults, perhaps owing to a reduction in pneumococcal transmission from children ${ }^{120}$. Therefore, although it might be too soon to draw conclusions about the ultimate effect of vaccines on antimicrobial resistance, they represent a potentially valuable tool for intervention.

In summary, antimicrobial resistance in the community setting is a multifactorial problem that is progressively increasing. To tackle this problem, we must take a multifaceted approach that focuses on, but is not limited to, reducing the volume of antimicrobial use wherever and whenever we can.
1. Rammelkamp, C. H. \& Maxon, T. Resistance of Staphylococcus aureus to the action of penicillin Proc. Royal Soc. Experim. Biol. Med. 51, 386-389 (1942).

2. Goossens, H., Ferech, M., Vander Stichele, R. $\delta$ Elseviers, M. Outpatient antibiotic use in Europe and association with resistance: a cross-national database study. Lancet 365, 579-587 (2005)

This article describes an important study that traces a strong epidemiological link between antibiotic use and resistance in various countries in Europe.

3. Mellon, M., Benbrook, C. \& Benbrook, K Hogging It: Estimates of Antimicrobial Abuse in Livestock (UCS Publications, Cambridge, 2001).

4. Gonzales, R., Steiner, J. F. \& Sande, M. A Antibiotic prescribing for adults with colds, upper respiratory tract infections, and bronchitis by ambulatory care physicians. JAMA 278, 901-904 (1997).

5. Nyquist, A. C., Gonzales, R., Steiner, J. F. \& Sande, M. A. Antibiotic prescribing for children with colds, upper respiratory tract infections, and bronchitis. JAMA 279, 875-857 (1998).

6. Watanabe, T. Infective heredity of multiple drug resistance in bacteria. Bacteriol. Rev. 27, 87-115 (1963).

7. Brown, D. F. \& Reynolds, P. E. Intrinsic resistance to $\beta$-lactam antibiotics in Staphylococcus aureus. FEBS Lett. 122, 275-278 (1980).

8. Stokes, H. W. $\&$ Hall, R. M. A novel family of potentially mobile DNA elements encoding sitespecific gene-integration functions: integrons. $\mathrm{Mol}$. Microbiol. 3, 1669-1683 (1989).

9. Griggs, D. J., Gensberg, K. \& Piddock, L. J. Mutations in gyrA gene of quinolone-resistant Salmonella serotypes isolated from humans and animals. Antimicrob. Agents Chemother. 40, 1009-1013 (1996).

10. Jorgensen, J. H., Weigel, L. M., Ferraro, M. J., Swenson, J. M. \& Tenover, F. C. Activities of newer fluoroquinolones against Streptococcus pneumoniae clinical isolates including those with mutations in the gyrA, parC, and parE loci. Antimicrob. Agents Chemother. 43, 329-334 (1999).

11. Kruse, H., Sorum, H., Tenover, F. C. \& Olsvik, O. A transferable multiple drug resistance plasmid from Vibrio cholerae O1. Microb. Drug Resist. 1, 203-210 (1995).

12. Sadowski, P., Peterson, B. C., Gerding, D. L. \& Cleary, P. P. Physical characterization of ten R plasmids obtained from an outbreak of nosocomial Klebsiella pneumoniae infections. Antimicrob. Agents Chemother. 15, 616-624 (1979)

13. Barza, M. \& Travers, K. Excess infections due to antimicrobial resistance: the "Attributable Fraction". Clin. Infect. Dis. 34, S126-S130 (2002).

This review outlines an interesting way of thinking about the impact of antimicrobial resistance on the number of infections.

14. Daum, R. S., Gupta, S., Sabbagh, R. \& Milewski, W. M. Characterization of Staphylococcus aureus isolates with decreased susceptibility to vancomycin and teicoplanin: isolation and purification of a constitutively produced protein associated with decreased susceptibility. J. Infect. Dis. 166, 1066-1072 (1992)
15. Sieradzki, K. \& Tomasz, A. Inhibition of cell wall turnover and autolysis by vancomycin in a highly vancomycin-resistant mutant of Staphylococcus aureus. J. Bacteriol. 179, 2557-2566 (1997).

16. Smith, T. L. et al. Emergence of vancomycin resistance in Staphylococcus aureus. Glycopeptide-Intermediate Staphylococcus aureus Working Group. N. Engl. J. Med. 340, 493-501 (1999).

17. Cui, L., Murakami, H., Kuwahara-Arai, K., Hanaki, H. \& Hiramatsu, K. Contribution of a thickened cell wall and its glutamine nonamidated component to the vancomycin resistance expressed by Staphylococcus aureus Mu50. Antimicrob. Agents Chemother. 44 2276-2285 (2000).

18. Gonzalez-Zorn, B. \& Courvalin, P. VanA-mediated high level glycopeptide resistance in MRSA. Lancet Infect. Dis. 3, 67-68 (2003).

19. Martinez, J. L. \& Baquero, F. Interactions among strategies associated with bacterial infection: pathogenicity, epidemicity, and antibiotic resistance. Clin. Microbiol. Rev. 15, 647-679 (2002)

20. Russell, A. D., Hammond, S. A. \& Morgan, J. R. Bacterial resistance to antiseptics and disinfectants. J. Hosp. Infect. 7, 213-225 (1986).

21. Anwar, H., Strap, J. L., Chen, K. \& Costerton, J. W. Dynamic interactions of biofilms of mucoid Pseudomonas aeruginosa with tobramycin and piperacillin. Antimicrob. Agents Chemother. 36 1208-1214 (1992)

22. Donlan, R. M. Biofilms and device-associated infections. Emerg. Infect. Dis. 7, 277-281 (2001).

23. O'Brien, L. M., Walsh, E. J., Massey, R. C., Peacock, S. J. \& Foster, T. J. Staphylococcus aureus clumping factor B (ClfB) promotes adherence to human type I cytokeratin 10: implications for nasal colonization. Cell. Microbiol. 4, 759-770 (2002)

24. Weidenmaier, C. et al. Role of teichoic acids in Staphylococcus aureus nasal colonization, a major risk factor in nosocomial infections. Nature Med. 10 243-245 (2004).

25. Bell, D. C., Montoya, I. D., Atkinson, J. S. \& Yang, S. J. Social networks and forecasting the spread of HIV infection. J. Acquir. Immune Defic. Syndr. 31 , 218-229 (2002).

26. Klovdahl, A. S. et al. Networks and tuberculosis: an undetected community outbreak involving public places. Soc. Sci. Med 52, 681-694 (2001).

27. Lowy, F. D. \& Miller, M. New methods to investigate infectious disease transmission and pathogenesis Staphylococcus aureus disease in drug users. Lance Infect. Dis. 2, 605-612 (2002).

28. Ward, H. et al. A prospective social and molecular investigation of gonococcal transmission. Lancet 356 , 1812-1817 (2000)

29. Burman, L. A., Norrby, R. \& Trollfors, B. Invasive pneumococcal infections: incidence, predisposing factors, and prognosis. Rev. Infect. Dis. 7, 133-142 (1985)

30. Hansman, D. \& Bullen, M. M. A resistant pneumococcus. Lancet 290, 264 (1967)

31. Zighelboim, S. \& Tomasz, A. Penicillin-binding proteins of multiply antibiotic-resistant South African strains of Streptococcus pneumoniae. Antimicrob. Agents Chemother. 17, 434-442 (1980).

32. Dowson, C. G., Coffey, T. J. \& Spratt, B. G. Origin and molecular epidemiology of penicillin-binding-protein mediated resistance to $\beta$-lactam antibiotics. Trends Microbiol. 2, 361-366 (1994).
33. Doern, G. V. Antimicrobial use and the emergence of antimicrobial resistance with Streptococcus pneumoniae in the United States. Clin. Infect. Dis. 33 S187-S192 (2001).

34. Doern, G. V. \& Brown, S. D. Antimicrobial susceptibility among community-acquired respiratory tract pathogens in the USA: data from PROTEKT US 2000-01. J. Infect. 48, 56-65 (2004).

35. Clavo-Sanchez, A. J. et al. Multivariate analysis of risk factors for infection due to penicillin-resistant and multidrug-resistant Streptococcus pneumoniae: a multicenter study. Clin. Infect. Dis. 24, 1052-1059 (1997).

36. Pallares, R. et al. Risk factors and response to antibiotic therapy in adults with bacteremic pneumonia caused by penicillin-resistant pneumococci. N. Engl. J. Med. 317, 18-22 (1987).

37. Albrich, W. C., Monnet, D. L. \& Harbarth, S. Antibiotic selection pressure and resistance in Streptococcus pneumoniae and Streptococcus pyogenes. Emerg. Infect. Dis. 10, 514-517 (2004).

38. Bronzwaer, S. L. et al. A European study on the relationship between antimicrobial use and antimicrobial resistance. Emerg. Infect. Dis. 8 , 278-282 (2002)

39. Corso, A., Severina, E. P., Petruk, V. F., Mauriz, Y. R. \& Tomasz, A. Molecular characterization of penicillinresistant Streptococcus pneumoniae isolates causing respiratory disease in the United States. Microb. Drug Resist. 4, 325-337 (1998)

40. Soares, S., Kristinsson, K. G., Musser, J. M. \& Tomasz, A. Evidence for the introduction of a multiresistant clone of serotype 6B Streptococcus pneumoniae from Spain to Iceland in the late $1980 \mathrm{~s}$. J. Infect. Dis. 168, 158-163 (1993).

41. Duchin, J. S. et al. High prevalence of multidrugresistant Streptococcus pneumoniae among children in a rural Kentucky community. Pediatr. Infect. Dis. J. 14, 745-750 (1995)

42. Neto, A. S. et al. Risk factors for the nasopharyngeal carriage of respiratory pathogens by Portuguese children: phenotype and antimicrobial susceptibility of Haemophilus influenzae and Streptococcus pneumoniae. Microb. Drug Resist. 9, 99-108 (2003).

43. Dudley, S., Ashe, K., Winther, B. \& Hendley, J. O Bacterial pathogens of otitis media and sinusitis: detection in the nasopharynx with selective agar media. J. Lab. Clin. Med. 138, 338-342 (2001).

44. McCormick, A. W. et al. Geographic diversity and temporal trends of antimicrobial resistance in Streptococcus pneumoniae in the United States. Nature Med. 9, 424-430 (2003).

These authors used mathematical modelling to weigh the relative impact of antibiotic selective pressure and clonal dissemination on antimicrobial resistance in S. pneumoniae in the United States.

45. McEwen, S. A. \& Fedorka-Cray, P. J. Antimicrobial use and resistance in animals. Clin. Infect. Dis. 34, S93-S106 (2002).

This review article presents a general overview of antimicrobial use in animals.

46. Levy, S. B., FitzGerald, G. B. \& Macone, A. B. Changes in intestinal flora of farm personnel after introduction of a tetracycline-supplemented feed on a farm. N. Engl. J. Med. 295, 583-588 (1976). This landmark study shows a link between antibiotic use in farm animals and antibiotic resistance in humans who live on the farm. 
47. Uttley, A. H., Collins, C. H., Naidoo, J. \& George, R. C. Vancomycin-resistant enterococci. Lancet 1, 57-58 (1988).

48. Aarestrup, F. M. et al. Glycopeptide susceptibility among Danish Enterococcus faecium and Enterococcus faecalis isolates of animal and human origin and PCR identification of genes within the VanA cluster. Antimicrob. Agents Chemother. 40 1938-1940 (1996).

49. Klare, I., Heier, H., Claus, H., Reissbrodt, R. \& Witte, W. vanA-mediated high-level glycopeptide resistance in Enterococcus faecium from animal husbandry. FEMS Microbiol. Lett. 125, 165-171 (1995).

50. Bates, J., Jordens, J. \& Griffiths, D. Farm animals as a putative reservoir for vancomycin-resistant enterococcal infection in man. J. Antimicrob. Chemother. 34, 507-514 (1994).

51. van den Bogaard, A. E., Jensen, L. B. \& Stobberingh, E. E. Vancomycin-resistant enterococci in turkeys and farmers. N. Engl. J. Med. 337 1558-1559 (1997)

52. Coque, T., Tomayko, J., Ricke, S., Okhyusen, P. \& Murray, B. Vancomycin-resistant enterococci from nosocomial, community, and animal sources in the United States. Antimicrob. Agents Chemother. 40 2605-2609 (1996).

53. Jordens, J. Z., Bates, J. \& Griffiths, D. T. Faecal carriage and nosocomial spread of vancomycinresistant Enterococcus faecium. J. Antimicrob. Chemother. 34, 515-528 (1994).

54. Klare, I., Heier, H., Claus, H. \& Witte, W. Environmental strains of Enterococcus faecium with inducible high level resistance to glycopeptides. FEMS Microbiol. Lett. 106, 23-29 (1993).

55. Mead, P. S., Slutsker, L., Griffin, P. M. \& Tauxe, R. V. Food-related illness and death in the United States reply to Dr Hedberg. Emerg. Infect. Dis. 5, 841-842 (1999).

56. White, D. G. et al. The isolation of antibiotic-resistant salmonella from retail ground meats. $N$. Engl. J. Med. 345, 1147-1154 (2001).

57. Blaser, M. J. \& Newman, L. S. A review of human salmonellosis: I. Infective dose. Rev. Infect. Dis. $\mathbf{4}$ 1096-1106 (1982).

58. Woodward, D. L., Khakhria, R. \& Johnson, W. M. Human salmonellosis associated with exotic pets. J. Clin. Microbiol. 35, 2786-2790 (1997)

59. CDC. Outbreak of multidrug-resistant Salmonella typhimurium associated with rodents purchased at retail pet stores - United States, December 2003October 2004. MMWR Morb. Mortal. Wkly Rep. 54, 429-433 (2005)

60. Threlfall, E. J. et al. Antimicrobial drug resistance in isolates of Salmonella enterica from cases of salmonellosis in humans in Europe in 2000: results of international multi-centre surveillance. Euro Surveill. 8, 41-45 (2003)

61. Casin, I. et al. Multidrug-resistant human and animal Salmonella typhimurium isolates in France belong predominantly to a DT104 clone with the chromosome- and integron-encoded $\beta$-lactamase PSE-1. J. Infect. Dis. 179, 1173-1182 (1999).

62. Ridley, A. \& Threlfall, E. J. Molecular epidemiology of antibiotic resistance genes in multiresistant epidemic Salmonella typhimurium DT 104. Microb. Drug Resist. 4, 113-118 (1998)

63. Threlfall, E. J., Frost, J. A., Ward, L. R. \& Rowe, B. Epidemic in cattle and humans of Salmonella typhimurium DT 104 with chromosomally integrated multiple drug resistance. Vet. Rec. 134, 577 (1994).

64. Hakanen, A., Kotilainen, P., Huovinen, P., Helenius, H. $\Sigma$ Siitonen, A. Reduced fluoroquinolone susceptibility in Salmonella enterica serotypes in travelers returning from Southeast Asia. Emerg. Infect. Dis. 7, 996-1003 (2001).

65. Isenbarger, D. W. et al. Comparative antibiotic resistance of diarrheal pathogens from Vietnam and Thailand, 1996-1999. Emerg. Infect. Dis. 8, 175-180 (2002)

66. Molbak, K., Gerner-Smidt, P. \& Wegener, H. C. Increasing quinolone resistance in Salmonella enterica serotype Enteritidis. Emerg. Infect. Dis. 8, 514-515 (2002).

67. Chiu, C. H. et al. The emergence in Taiwan of fluoroquinolone resistance in Salmonella enterica serotype choleraesuis. N. Engl. J. Med. 346 413-419 (2002)

68. National Antimicrobial Resistance Monitoring System for Enteric Bacteria: Annual Report, 2001 (Centers for Disease Control and Prevention, Atlanta, 2001).
69. Threlfall, E. J., Graham, A., Cheasty, T., Ward, L. R. \& Rowe, B. Resistance to ciprofloxacin in pathogenic Enterobacteriaceae in England and Wales in 1996 J. Clin. Pathol. 50, 1027-1028 (1997).

70. Cody, S. H. et al. Two outbreaks of multidrug-resistant Salmonella serotype typhimurium DT104 infections linked to raw-milk cheese in Northern California. JAMA 281, 1805-1810 (1999).

71. Villar, R. G. et al. Investigation of multidrug-resistant Salmonella serotype typhimurium DT104 infections linked to raw-milk cheese in Washington State. JAMA 281, 1811-1816 (1999)

72. Threlfall, E. J. Antimicrobial drug resistance in Salmonella: problems and perspectives in food- and water-borne infections. FEMS Microbiol. Rev. 26 , $141-148$ (2002)

73. Piddock, L. J. Fluoroquinolone resistance in Salmonella serovars isolated from humans and food animals. FEMS Microbiol. Rev. 26, 3-16 (2002).

74. Threlfall, E. J., Ward, L. R., Skinner, J. A. \& Rowe, B. Increase in multiple antibiotic resistance in nontyphoidal salmonellas from humans in England and Wales: a comparison of data for 1994 and 1996. Microb. Drug Resist. 3, 263-266 (1997).

75. Olsen, S. J. et al. A nosocomial outbreak of fluoroquinolone-resistant salmonella infection. N. Engl. J. Med. 344, 1572-1579 (2001).

76. Aarestrup, F. M. et al. Effect of abolishment of the use of antimicrobial agents for growth promotion on occurrence of antimicrobial resistance in fecal enterococci from food animals in Denmark. Antimicrob. Agents Chemother. 45, 2054-2059 (2001). This study shows a decrease in VRE in food animals in Denmark after a ban on the use of virginiamycin

77. Wierup, M. The Swedish experience of the 1986 year ban of antimicrobial growth promoters, with special reference to animal health, disease prevention, productivity, and usage of antimicrobials. Microb. Drug Resist. 7, 183-190 (2001).

78. Casewell, M W. \& Hill, R. L. The carrier state: methicillin-resistant Staphylococcus aureus. J. Antimicrob. Chemother. 18 (Suppl. A), 1-12 (1986)

79. Noble, W. C., Valkenburg, H. A. \& Wolters, C. H. Carriage of Staphylococcus aureus in random samples of a normal population. J. Hyg. (Lond.) 65, 567-573 (1967).

80. Wenzel, R. P. \& Perl, T. M. The significance of nasal carriage of Staphylococcus aureus and the incidence of postoperative wound infection. J. Hosp. Infect. 31 13-24 (1995).

81. Tuazon, C. U., Perez, A., Kishaba, T. \& Sheagren, J. N. Staphylococcus aureus among insulin-injecting diabetic patients. An increased carrier rate. JAMA 231, 1272 (1975)

82. Tuazon, C. U. \& Sheagren, J. N. Increased rate of carriage of Staphylococcus aureus among narcotic addicts. J. Infect. Dis. 129, 725-727 (1974).

83. Yu, V. L. et al. Staphylococcus aureus nasal carriage and infection in patients on hemodialysis. Efficacy of antibiotic prophylaxis. N. Engl. J. Med. 315, 91-96 (1986)

84. Weinstein, H. J. The relation between the nasalstaphylococcal-carrier state and the incidence of postoperative complications. N. Engl. J. Med. 260 1303-1308 (1959)

85. Weinke, T., Schiller, R., Fehrenbach, F. J. \& Pohle, H. D. Association between Staphylococcus aureus nasopharyngeal colonization and septicemia in patients infected with the human immunodeficiency virus. Eur. $J$. Clin. Microbiol. Infect. Dis. 11, 985-989 (1992).

86. Jevons, M. P., Coe, A. W. \& Parker, M. T. Methicillin resistance in staphylococci. Lancet 1, 904-907 (1963).

87. National Nosocomial Infections Surveillance System National Nosocomial Infections Surveillance (NNIS) System Report, data summary from January 1992 through June 2004, issued October 2004. Am. J. Infect. Control 32, 470-485 (2004).

88. Tiemersma, E. W. et al. Methicillin-resistant Staphylococcus aureus in Europe, 1999-2002. Emerg. Infect. Dis. 10, 1627-1634 (2004).

89. Crisostomo, M. I. et al. The evolution of methicillin resistance in Staphylococcus aureus: similarity of genetic backgrounds in historically early methicillinsusceptible and -resistant isolates and contemporary epidemic clones. Proc. Natl Acad. Sci. USA 98 9865-9870 (2001)

These authors used molecular techniques to trace the evolution of meticillin resistance in S. aureus.
90. Enright, M. C. et al. The evolutionary history of methicillin-resistant Staphylococcus aureus (MRSA). Proc. Natl Acad. Sci. USA 99, 7687-7692 (2002).

91. Udo, E. E., Pearman, J. W. \& Grubb, W. B. Genetic analysis of community isolates of methicillin-resistant Staphylococcus aureus in Western Australia. J. Hosp. Infect. 25, 97-108 (1993)

92. Fridkin, S. K. et al. Methicillin-resistant Staphylococcus aureus disease in three communities. N. Engl. J. Med. 352, 1436-1444 (2005). This study is a population-based analysis of MRSA in different communities in the United States.

93. CDC. Four pediatric deaths from community-acquired methicillin-resistant Staphylococcus aureus Minnesota and North Dakota, 1997-1999. MMWR Morbid. Mortal. Wkly Rep. 48, 707-710 (1999).

94. Lina, G. et al. Involvement of Panton-Valentine leukocidin-producing Staphylococcus aureus in primary skin infections and pneumonia. Clin. Infect. Dis. 29, 1128-1132 (1999).

95. Miller, L. G. et al. Necrotizing fasciitis caused by community-associated methicillin-resistant Staphylococcus aureus in Los Angeles. N. Engl. J. Med. 352, 1445-1453 (2005).

96. Daum, R. S. et al. A novel methicillin-resistance cassette in community-acquired methicillin-resistant Staphylococcus aureus isolates of diverse genetic backgrounds. J. Infect. Dis. 186, 1344-1347 (2002).

97. Hiramatsu, K., Katayama, Y., Yuzawa, H. \& Ito, T. Molecular genetics of methicillin-resistant Staphylococcus aureus. Int. J. Med. Microbiol. 292 67-74 (2002).

98. Ma, X. X. et al. Novel type of staphylococcal cassette chromosome mec identified in community-acquired methicillin-resistant Staphylococcus aureus strains. Antimicrob. Agents Chemother. 46, 1147-1152 (2002).

99. Okuma, K. et al. Dissemination of new methicillinresistant Staphylococcus aureus clones in the community. J. Clin. Microbiol. 40, 4289-4294 (2002).

100. Calfee, D. P. et al. Spread of methicillin-resistant Staphylococcus aureus (MRSA) among household contacts of individuals with nosocomially acquired MRSA. Infect. Control Hosp. Epidemiol. 24, 422-426 (2003).

101. Saiman, L. et al. Hospital transmission of communityacquired methicillin-resistant Staphylococcus aureus among postpartum women. Clin. Infect. Dis. 37, 1313-1319 (2003)

102. Archer, G. L. \& Niemeyer, D. M. Origin and evolution of DNA associated with resistance to methicillin in staphylococci. Trends Microbiol. 2, 343-347 (1994).

103. Baba, T. et al. Genome and virulence determinants of high virulence community-acquired MRSA. Lancet 359, 1819-1827 (2002)

104. Robinson, D. A et al. Re-emergence of early pandemic Staphylococcus aureus as a community-acquired meticillin-resistant clone. Lancet 365, 1256-1258 (2005).

This study used multilocus sequence analysis to show that one of the important CA-MRSA clones might be descended from an early penicillinresistant meticillin-sensitive Staphylococcus aureus clone.

105. CDC. Methicillin-resistant Staphylococcus aureus skin or soft tissue infections in a state prison Mississippi, 2000. MMWR Morb. Mortal. Wkly Rep. 50, 919-922 (2001)

106. Charlebois, E. D. et al. Origins of community strains of methicillin-resistant Staphylococcus aureus. Clin. Infect. Dis. 39, 47-54 (2004).

107. Herold, B. C. et al. Community-acquired methicillinresistant Staphylococcus aureus in children with no identified predisposing risk. JAMA 279, 593-598 (1998).

108. Nguyen, D. M., Mascola, L. \& Brancoft, E. Recurring methicillin-resistant Staphylococcus aureus infections in a football team. Emerg. Infect. Dis. 11, 526-532 (2005).

109. Zinderman, C. E. et al. Community-acquired methicillin-resistant Staphylococcus aureus among military recruits. Emerg. Infect. Dis. 10, 941-944 (2004).

110. Enne, V. I., Livermore, D. M., Stephens, P. \& Hall, L. M. Persistence of sulphonamide resistance in Escherichia coli in the UK despite national prescribing restriction. Lancet 357, 1325-1328 (2001). 
111. Seppala, H. et al. The effect of changes in the consumption of macrolide antibiotics on erythromycin resistance in group A streptococci in Finland. Finnish Study Group for Antimicrobial Resistance. N. Engl. J. Med. 337, 441-446 (1997).

These authors describe the positive effects of a national guideline to limit macrolide use in Finland on macrolide resistance in group A streptococci.

112. Guillemot, D. et al. Low dosage and long treatment duration of $\beta$-lactam: risk factors for carriage of penicillin-resistant Streptococcus pneumoniae. JAMA 279, 365-370 (1998)

113. Schrag, S. J. et al. Effect of short-course, high-dose amoxicillin therapy on resistant pneumococcal carriage a randomized trial. JAMA 286, 49-56 (2001).

114. Day, S., Ward, H., Ison, C., Bell, G. \& Weber J. Sexual networks: the integration of social and genetic data. Soc. Sci. Med. 47, 1981-1992 (1998).

115. Hoberman, A. et al. Penicillin susceptibility of pneumococcal isolates causing acute otitis media in children: seasonal variation. Pediatr. Infect. Dis. J. 24 115-120 (2005)

116. Karlowsky, J. A. et al. Factors associated with relative rates of antimicrobial resistance among Streptococcus pneumoniae in the United States: results from the TRUST Surveillance Program (1998-2002). Clin. Infect. Dis. 36, 963-970 (2003).

117. Mera, R. M., Miller, L. A., Daniels, J. J., Weil, J. G. \& White, A. R. Increasing prevalence of multidrugresistant Streptococcus pneumoniae in the United States over a 10-year period: Alexander Project. Diagn. Microbiol. Infect. Dis. 51, 195-200 (2005)

118. Temime, L., Guillemot, D. \& Boelle, P. Y. Short- and longterm effects of pneumococcal conjugate vaccination of children on penicillin resistance. Antimicrob. Agents Chemother. 48, 2206-2213 (2004)

119. Kaplan, S. L. et al. Decrease of invasive pneumococca infections in children among 8 children's hospitals in the United States after the introduction of the 7-valent pneumococcal conjugate vaccine. Pediatrics 113, 443-449 (2004).

120. Whitney, C. G. et al. Decline in invasive pneumococcal disease after the introduction of proteinpolysaccharide conjugate vaccine. N. Engl. J. Med. 348, 1737-1746 (2003).

This study shows a decrease in pneumococcal disease in both children and adults after the introduction of the pneumococcal conjugate vaccine.
121. Jacobs, M. R. et al. Susceptibilities of Streptococcus pneumoniae and Haemophilus influenzae to 10 oral antimicrobial agents based on pharmacodynamic parameters: 1997 U. S. Surveillance study. Antimicrob. Agents Chemother. 43, 1901-1908 (1999).

122. Espinosa de los Monteros, L. E., Bustos, I. M. Flores, L. V. \& Avila-Figueroa, C. Outbreak of scarlet fever caused by an erythromycin-resistant Streptococcus pyogenes emm22 genotype strain in a day-care center. Pediatr. Infect. Dis. J. 20, 807-809 (2001).

123. Holmstrom, L., Nyman, B., Rosengren, M., Wallander, S. \& Ripa, T. Outbreaks of infections with erythromycin-resistant group A streptococci in child day care centres. Scand. J. Infect. Dis. 22, 179-185 (1990)

124. Critchley, I. A. et al. Antimicrobial susceptibilities of Streptococcus pyogenes isolated from respiratory and skin and soft tissue infections: United States LIBRA surveillance data from 1999. Diagn. Microbiol. Infect. Dis. 42, 129-135 (2002).

125. Tanz, R. R. et al. Community-based surveillance in the United States of macrolide-resistant pediatric pharyngeal group A streptococci during 3 respiratory disease seasons. Clin. Infect. Dis. 39, 1794-1801 (2004).

126. Martin, J. M., Green, M., Barbadora, K. A. \& Wald, E. R. Erythromycin-resistant group A streptococci in schoolchildren in Pittsburgh. N. Engl. J. Med. 346 1200-1206 (2002)

127. Groom, A. V. et al. Community-acquired methicillinresistant Staphylococcus aureus in a rural American Indian community. JAMA 286, 1201-1205 (2001).

128. Charlebois, E. D. et al. Population-based community prevalence of methicillin-resistant Staphylococcus aureus in the urban poor of San Francisco. Clin. Infect. Dis. 34, 425-433 (2002).

129. Hisata, K. et al. Dissemination of methicillin-resistant staphylococci among healthy Japanese children. J. Clin. Microbiol. 43, 3364-3372 (2005).

130. Pan, E. S. et al. Population dynamics of nasal strains of methicillin-resistant Staphylococcus aureus - and their relation to community-associated disease activity. J. Infect. Dis. 192, 811-818 (2005).

131. Muder, R. R. et al. Methicillin-resistant staphylococcal colonization and infection in a long-term care facility. Ann. Intern. Med. 114, 107-112 (1991).
132. Morris, J. G. Jr et al. Enterococci resistant to multiple antimicrobial agents, including vancomycin. Establishment of endemicity in a university medical center. Ann. Intern. Med. 123, 250-259 (1995).

133. Bates, J., Jordens, J. Z. \& Griffiths, D. T. Farm animals as a putative reservoir for vancomycin-resistant enterococcal infection in man. J. Antimicrob. Chemother. 34, 507-514 (1994).

134. Bhuiyan, B. U. et al. Antimicrobial susceptibilities and plasmid contents of Neisseria gonorrhoeae isolates from commercial sex workers in Dhaka, Bangladesh: emergence of high-level resistance to ciprofloxacin. J. Clin. Microbiol. 37, 1130-1136 (1999).

135. Fornasini, M., Reves, R. R., Murray, B. E., Morrow, A. L. \& Pickering, L. K. Trimethoprim-resistant Escherichia coli in households of children attending day care centers. J. Infect. Dis. 166, 326-30 (1992).

136. Smith, K. E. et al. Quinolone-resistant Campylobacter jejuni infections in Minnesota, 1992-1998. Investigation Team. N. Engl. J. Med. 340 , 1525-1532 (1999).

Acknowledgements

E.Y.F. is supported by a National Institutes of Health (NIH) training grant. F.D.L. is supported by grants from the Center for Disease Control and Prevention, NIH Grants and by a grant from the National Center for Research Resources, NIH, that supports the Center for Interdisciplinary Research on Antimicrobial Resistance.

Competing interests statement

The authors declare no competing financial interests.

DATABASES

The following terms in this article are linked online to:

Entrez: http://www.ncbi.nlm.nih.gov/Entrez

Clostridium difficile |Pseudomonas aeruginosa $\mid$ Salmonella

Typhimurium DT104 | Staphylococcus aureus | Staphylococcus

epidermidis | Streptococcus pneumoniae

FURTHER INFORMATION

Alliance for the Prudent Use of Antibiotics:

http://www.tufts.edu/med/apua

FDA bans enrofloxacin use in poultry:

http://www.fda.gov/bbs/topics/news/2005/new01212.html NARMS: http://www.cdc.gov/narms

Access to this interactive links box is free online. 